\title{
Pragma-Semantic Relations in the Structure of a Business Microblog
}

\author{
Alexandra V. Radyuk ${ }^{1}$, Maria V. Ivanova ${ }^{2}$, Darima A. Badmatsyrenova ${ }^{1} \&$ Vasily S. Makukha $^{1}$ \\ ${ }^{1}$ Peoples' Friendship University of Russia (RUDN University), Moscow, Russia \\ ${ }^{2}$ Maxim Gorky Institute of Literature and Creative Writing, Russia \\ Correspondence: Alexandra Radyuk, Senior Lecturer of Foreign Languages Department, Faculty of Economics, \\ Peoples' Friendship University of Russia (RUDN University), 117198, Miklukho-Maklaya str. 6, Moscow, \\ Russia. E-mail: radyuk-av@rudn.ru
}

Received: September 28, 2019 Accepted: October 25, 2019 Online Published: November 12, 2019

doi:10.5539/ijel.v9n6p392 URL: https://doi.org/10.5539/ijel.v9n6p392

\begin{abstract}
The article considers the business microblog as a new business communication register and studies its structural and semantic properties. The relevance of the work is determined by the fact that at present the microblog register in the context of business communication and its semantic structure are not fully studied. The authors aim to find out what pragmatic, structural and semantic features are peculiar to business messages in social network Twitter. Using the methods of discourse analysis, semantic and linguosynergetic analysis, we identified such structural properties of business microblogs as hypertextuality, interactivity, spontaneity, business context, dialogism, situationality and expressiveness. Semantic properties include most frequent pragma-semantic relations between propositions in microblogs (explanation, expansion, causation, pragmatic commentary). The language material shows that the genre of business microblogging is the result of mixing and contamination of oral and written registers of business discourse, as well as the emergence of new technical means of communication. A linguosynergetic analysis of propositions showed that the semantic structure is determined by the communicative intention of the addressee and, due to the small volume of messages, is based on two or three propositions connected by certain logical relationships. Further research on this topic can be carried out in the field of studying other genres and the influence of addressee factor in online communication.
\end{abstract}

Keywords: business discourse, discourse analysis, linguosynergetics, microblog, stylistics, system

\section{Introduction}

\subsection{Statement of the Problem}

This paper explores the problem of the structural-semantic organisation of the message in a business microblog from the point of view of its conditioning by the business pragmatics of such a message.

The topicality of the present research is due to the need to describe the mechanisms of the functional perspective of business discourse evolution in this understudied and relatively young speech register - the business microblog.

The study is a continuation of work in the field of functional pragmatics of English business discourse (Malyuga, \& Tomalin, 2017; Malyuga, 2019; Malyuga, 2020; Kharkovskaya, Ponomarenko, \& Radyuk, 2017; Lebedeva \& Orlova, 2019; Litvinov, Burikova, \& Khramchenko, 2017; Malakhova, 2017; Khramchenko, 2015). Using a linguosynergetic approach to the study of oral and written business speech, we have developed a classification of discursive strategies according to the criterion of enhancing and weakening of pragmatic impact, concealment and openness of impact. Continuing to investigate various manifestations of business discourse functioning as a synergistic system of meanings, in this paper we turn to the field of online communication.

Linguists emphasise the particular relevance of the study of genres which are subject to contamination-a mixture of traits characteristic of different styles. However, not only their structural originality is interesting, but also the speech influence potential, taking into account the small volume of messages in a business microblog.

The main hypothesis is that small-format texts, united by the topic of business activity, are organised according to a certain set of logical and semantic relations. The secondary hypothesis suggests that this register limits the set of special order parameters in the pragma-semantic system of small-format text to several most frequent ones.

The theoretical significance of the study is that it expands the range of studies on linguosynergetics and 
functional pragmatics of business discourse, its results can be useful in theoretical courses on the stylistics and rhetorics of the English language. The practical value lies in the development of effective business communication skills on the Internet, in formal and informal registers.

\subsection{Importance of the Problem}

Having an applied nature, the present research is caused by interest in functioning of speech tools in small-format texts. In modern communication, the exchange of information is fast and concise. Business speech is characterised by a high degree of implicitness, content richness and hidden meanings (Ponomarenko, 2016).

How to communicate online on business topics, catching all the background information? How to speak/write briefly and effectively? How to convincingly articulate your attitude and form a certain vision of facts? How to present information, putting forward the necessary and veiling undesirable facts? Practical knowledge of these skills is necessary for any specialist in the field of professional communication who wants to achieve success in his professional field.

In this regard, the authors aim to find out how the functional-pragmatic organisation of speech helps to perform these functions in business messages in a social network.

To do this, the following tasks are solved in the article:

- to study the corpus of business messages in social networks, united by the topic of business;

- to substantiate the application of the methods of functional linguosynergetics to the analysis of small-format texts of social networks;

- to describe structural and semantic features of the business microblogging;

- basing on the classification of functional connections (relationships) in the discourse system, to identify which functional relationships are most frequent in the analysed posts, and determine their functions.

\subsection{Relevant Scholarship}

Today, functional linguistics has established an understanding of discourse as a communicative event, as Halliday and Hasan succinctly defined it- "the total event, in which the text is functioning, together with the purposive activity of the speaker or writer" (Halliday \& Hasan, 1974, p. 22). However, discourses rarely exist in their pure form; in the circumstances of real functioning new discourses and genres are combining features of oral and written, colloquial and formal communication (Bhatia, 1993). The study of works in the field of discourse analysis, on stylistics and psycholinguistics led to the definition of online discourse as a special type of discourse that combines the features of oral and written forms and has the functions of self-presentation, information, persuasion, etc. (Gunnarson, 2014; Runkehl, 2018).

Modern communication tools offer the business community a new communication channel that allows to instantly exchange messages and receive feedback from audiences of various sizes.

A review of works on this topic indicates that the microblogging register in the context of business communication and its semantic structure have not been extensively studied.

So, Barkovich (2015) writes that some stylistic features are described by linguists, but further study and modeling of the speech practice of the global network is necessary. He classifies metalanguage models (prototypical communication patterns) in a phenomenological aspect and identifies pragmatic, social and personality groups of models (Ibid. p. 177). Such metalanguage models as Internet surfing, trolling, flood, flame, friendship, liking, crowdsourcing (Jenks, 2019; Gritsenko \& Demidova, 2018).

The microblogging genre has been studied relatively recently. Eleta and Golbeck (2014) see the task of microblogging as harmonization of the international communication space. Looking at Twitter in a sociolinguistic perspective, they built a typology of networks based on the characteristic connections in the multilingual groups of social networks and determined their verbal expression.

Pérez-Llantada (2016) uses the term information access behavior for characterising modern peculiarities of transmitting information, emphasising that we can talk about a particular type of behavior in the interaction of an individual with the world of digital information. The author emphasises that the new ecology of the genres of online communication is the basis of its features such as iterdiscursiveness, hypertextuality, anonymity, emotional coloring and multimodality.

Linguists emphasise the relationship of microblogging with extralinguistic factors. Boldovskaya and Zvonova (2015) stress that age can be identified based on the speech characteristics of a communicant. They distinguish the following functions of microblogs: communicative function, function of establishing contacts, information 
function, self-presentation function, broadening horizons function, relaxation function. Thus, in terms of stylistics, virtual speech is a combined secondary genre. The dimensions of such genres are being actively investigated by quantitative methods. For example, Sardinha (2018) highlights the expression of stance and its two varieties that are important for online communication genres-interactional evidentiality and interactional affect. Thus, when expressing a position, the dominant role of the pragmatics of online communication and main role of the communicative intention leading to speech impact is again justified.

Nikitina, Gudkova and Sander (2018) explore the emotional nature of online communication and the Internet meme genre. They distinguish viral distribution, polycode nature and linguistic and cultural conditionality as one of its features. Like any other synchronous communication, in communication on the Internet the process of generation and inference of meaning occurs in the course of collective semiosis (Savitsky \& Ivanova, 2018).

In examining the semiosis process in business and, in particular, online discourse, we rely on the postulates of functional linguosynergetics, according to which the semantic system of expression is a system of meanings organised in accordance with the laws of open self-developing (synergetic) systems (Haken, 1996; Halliday, 2004; Wildgen, 1990), which is explored in linguistics by Ponomarenko (2004, 2016, 2018), Khramchenko (2018), Malakhova (2017), Radyuk and Litvinov (2018).

The method of linguosynergetic analysis is based on the assertion that the functional-pragmatic organisation of discourse is systemic (Ponomarenko, 2018). The communicative goal of the utterance serves as a functional attractor - the sphere of concentration of the pragmatic potential of multidirectional speech means (Malakhova, 2017, Khramchenko, 2019). Pragma-semantic relations between statements, arranged in a certain sequence, serve as order parameters and control the functioning of the system. Fluctuations occur under the influence of dynamic oscillations inside and outside the system. At the bifurcation point, the discourse system approaches the choice of the path of further development (either achieving a communicative goal or communicative failure) (Ponomarenko, 2016).

So, the current state of research on the problems of Internet discourse, genre studies and functional linguosynergetics leads us to consideration of the status of pragma-functional organisation of business communication in social networks.

\section{Method}

\subsection{Sampling Procedures}

As an empirical material, we selected158 examples of tweets from business microblogs of CBI (Confederation of British Industries), American Business Systems, CNN Business, the Washington Post, The Economist, The Financial Times for the first half of 2019.

\subsection{Research Design}

The study was carried out in the framework of dynamic-systemic approach and functional pragmatics. Self-regulatory properties of discourse were studied by the method of functional synergetic analysis developed by Ponomarenko $(2016,2018)$. It includes the following steps. First, the basic statement of the communicative block (topic), the attractor (communicative goal) of the sense system, the order parameters (functional relationships between propositions) are determined. Further, the general trends of the structural-semantic organisation of discourse and particular processes and phenomena of the functional plan are analysed (a description of the stages of discourse evolution, the role of language tools in creating functional properties on its way to the attractor, chaotic elements of the discourse and their place in the development of the system of meanings, stabilising elements and factors, pushing the system to transition, revealing the spontaneous properties of discourse). As a result, data are generalised in a synergetic model of this discourse.

It is necessary to define some concepts that we operate in the course of the study.

The central concept in linguosynergetics is a discourse system, understood as a system of discourse meanings, formed by a combination of means of their speech expression, aimed at achieving a communicative goal (attraction zone, "functional attractor") and possessing self-regulatory properties (Ponomarenko, 2004).

The synergy of discourse is understood as the effect of the addition of meanings, giving "not a sum of meanings, but new meanings" (according to Shcherba). In other words, such an effect, when the general meaning is not equal to the mechanical addition of the components, is called the functional non-linearity of the discourse.

In the genre of online communication, this property is especially evident when accompanied by messages with images and hyperlinks. For example, the Washington Post presented the title of an analytical article about a new application using a toy character. 


\section{Is that a gruesome "Sesame street" segment? No, it's an ad for the dating app Hinge.}

After the title there is an image of a burning toy and a hyperlink to the article. The functional nonlinearity of the system of this discourse allows the author to convey his intention: the design of the application is original and causes confusing associations in a certain circle of people.

A functional attractor (the communicative goal of discourse) is the message about a new application. The pragmatic potential of all components of this message is directed to it:

- verbal (a proper name — realia word "Sesame street"; a combination of a question and an answer; a deictic element that referring to an image);

- graphic (image of a toy that resembles a character of a cartoon known to one age category).

Without an image, the meaning of the above statements would not be understandable to the audience, despite the fact that individual proposals communicate certain information. Perceiving the discourse synergetically, in the aggregate, the reader correlates the content of verbal components with the image and his background knowledge (the lack of information about the cartoon will not allow the reader to extract the meaning or understand completely). Thanks to this multichannel, volumetric perception inherent in human thinking, the author more effectively conveys the meaning to the communicant. The system of meanings reaches the functional attractor.

Having analyzed the following example, we will see that this statement contains an unlimited number of semantic combinations. Depending on their organisation, the discourse system can restore the integrity of its functional space and achieve its communicative goal.

Self-organisation of discourse is manifested in pragma-semantic evolution of the meanings of the system. So, in the above example, a linear perception of information will cause conflict and misunderstanding. However, when external influences are involved (interaction with the external environment), the general meaning of the discourse is perceived not only as the addition of consecutive propositions, but as an accumulated cognitive-functional space. Each constituent plays its role as a semantic "amplifier" of the previous state and subsequent states of the semantic system.

Another term, chaotisation, is used to denote functional fluctuations, pragma-semantic increments that do not correspond to the original direction of the evolution of the system. Such an element may be the name of the cartoon, unfamiliar to some readers due to the transition of the common noun Sesame into the category of proper names.

In order not to exceed the optimal proportion of chaotic elements and to prevent complete disordering and the discourse system to move away from the desired direction of semantic evolution (and, as a result, disruption of the communicative concept), in contrast to chaotic trends in the synergy of the discourse, there are stabilising factors - order parameters. These include functional relationships between statements (according to van Dijk) (Dijk, 1981), i.e. semantic relations in their functioning.

This methodology allowed us to examine more closely some order parameters inherent in the business register in Internet communication.

\section{Results}

In the course of the work, the structural properties of the business microblogs (their distinctive stylistic features) were revealed.

\subsection{Structural Properties}

The studies of the microblog discourse are conducted today in the context of the theory of speech genres, as part of an interactive and functional approach. Being a modified speech genre, it is considered as part of the Internet discourse (Akhrenova, 2011, p. 119). Cognitive approach explores characteristics of a virtual linguistic personality. The genre and word-formation features of Internet communication are being analysed. Also, in the framework of functional linguistics, the purpose of various paralinguistic signs of computer-mediated communication is being investigated.

Linguists point out the important role of emoji in the structural organisation of the text to indicate the beginning and end of the text, design humorous turns and increase the expressiveness of speech (Samprieto, 2019; Scalzilli, 2018). Thus, the stylistic nature of paralinguistic signs is emphasized. Other pragmatic functions include demonstrating the degree of categorisation, mitigating the threat, and enhancing the pragmatic impact.

The microblogging genre features are small volume and informational density. As a rule, a microblog post is written to report news or share information. At the same time, a peculiarity of the Internet microblogging is 
agrammatism and disregard for the rules of syntax. Almost half of microblogging users "write illiterately" (Perevezentseva, 2014, p. 86).

Business microblogging is often an exception to this pattern. Being the official pages of various public organisations or the media, they mostly follow grammar and syntactic rules. And yet, the comments on tweets may contain most of the errors, which indicates the simplification and prevalence of American English on the Internet. So, spelling errors can be encountered, e.g.,

Definitely the best moment of the entire game. Second was big boi saying "hey ho"

In the field of grammar, we can observe simplification of tenses, omission of articles.

The American Dream is real. About as real as emigrate being the word you wanted to use there

Non-compliance with syntactic norms and intentional capitalisation are widespread to attract attention (Dubovsky \& Zagrayevskaya, 2018).

Everybody Knows Sarah H. Lied For Trump Until No On Believed A Word She Said \& Like He Does With Everyone He Can No Longer Use...He Tweets Her Departure In 2 Weeks... Is FOX Hiring...???

One of the main features of online discourse is its multimedia nature. Multimedia is a combination of heterogeneous information formats in one media resource. Text, sound, photo and video formats are used in online discourse (Nikitina \& Gudkova, 2018). Technical advances of modern Internet environment make it possible to use any media types. Microblogging involves all sorts of combinations - verbal and visual components, hyperlinks, videos, emoticons. From a linguistic point of view, multimedia messages of this kind are polycode.

Currently, the study of communicative messages of polycode nature are increasingly relevant because there are more texts that are different from traditional ones.

Still in spite of this fact scientists note that "the presence of non-verbal (or, as it is often called, with reference to a written text, paralinguistic) signs in the text does not yet indicate its polycode nature: a text is polycode if it is a paralinguistically active text, i.e., where paralinguistic means are carriers of information or at least add additional shades to the content" (Orlova, http). So, additional shades in the tweet content can be introduced by hashtags, links to video or images, capitalization, including emoticons and gifs, hyperlinks to the full text of the article, etc.

The non-verbal component of the microblog text, being one of the main components of this kind of texts, reinforces its pragmatic potential. For example, the image allows the author of the text covertly express his thoughts, while the reader is free to interpret the received message in the form of mixed codes information. Illustrative material performs not only informative, but also emphatic and expressive functions.

\subsection{Semantic Properties}

Also, semantic properties were revealed (reflecting the most frequent pragma-semantic relations between propositions in a small-format text).

The pragma-semantic properties of business electronic discourse were analysed by the method of functional analysis with elements of logical-semantic analysis. According to Ponomarenko (2011), consideration of discourse as a system implies identification of its structural and semantic components.

Functional relationships provide the logic for deploying the speaker's reasoning. The functional perspective of discourse develops evolutionarily, from the initial state to a new level of order under the guidance of a functional attractor - the purpose of the utterance. So, traditionally the functional relationships are divided into general and special.

\subsubsection{General Order Parameters}

The first type includes identity, inclusion, intersection, subordination and exclusion. The discourse order parameters characterise its functional connections (relations), that is, the relations of utterances to each other, their functional connections between propositions. General order parameters are represented by logical-semantic relations between propositions: identity - a double designation of the same referent situation, inclusion - the volume of one statement completely absorbs the volume of another one, intersection-one part of the proposition is duplicated, and another part remains its own for each correlate, subordination-propositions are included as components in the scope of a more general description of the referent, exception-propositions of compared statements do not have common elements.

Identity is extremely rare in the genre of microblog messages. Being a double designation of some phenomenon, 
identity repeats its description in other words. The volume of a Twitter post does not allow use semantic repetition, aimed at the goal of communicating as much information as possible in a compressed form. Most often there are one or two sentences.

Inclusion is quite widespread and represents a situation where the semantics of one of the propositions includes the semantics of the other. Let us consider a message that includes a statement about a decline in the position of US stocks.

CNN Business @CNNBusiness US stocks ended slightly lower on Tuesday. The Dow snapped a six-day winning streak, which hadn't been seen since May 2018. The Dow closed down 0.1\%, or 14 points. The S\&P 500 and the Nasdaq Composite closed flat in negative territory.

The tweet is based on the following propositions:

a) There is a decline in stock prices.

b) The first type of shares declined for the first time since May.

c) The first type of shares amounted to 14 points.

d) The second type of stock remained consistently low.

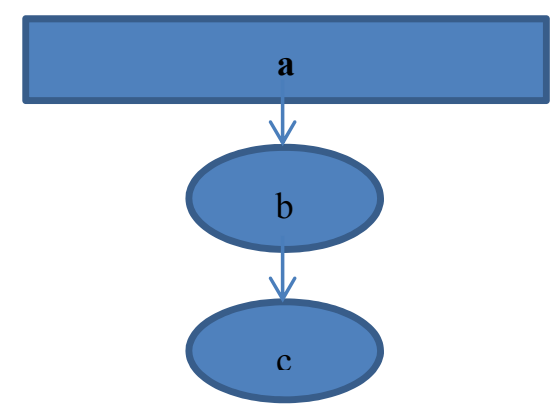

Figure 1. General order parameter-inclusion $(b-c)$

It can be seen from the diagram that the logical connections between propositions a and $\mathrm{b}$, a and $\mathrm{c}$ are in the relationship of subordination and proposition $\mathrm{c}$ follows from $\mathrm{b}$. The above example has the function of informing, which is why its structure is rather cumbersome compared to regular twitter messages.

Accordingly, intersection occurs when part of the proposition is duplicated, and part remains its own for each correlate, and exception takes place when the propositions of the compared statements do not have common elements. So, in the following example, intersection is observed in the meaning of propositions $\mathrm{b}$ and $\mathrm{c}$.

The Economist (@TheEconomist): Michael O'Sullivan, a former banker and economist, offers a roadmap for a post-globalisation world.

a) There is a person called M. Sullivan.

b) M. Sullivan has an expertise of an economic expert.

c) M. Sullivan gives advice on future economic development.

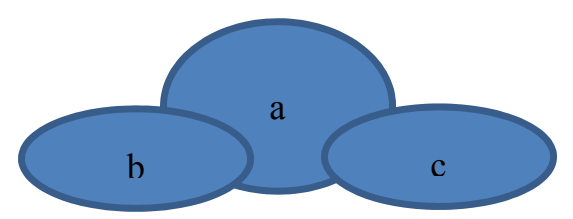

Figure 2. General order parameter-intersection

These relationships are used to explain and communicate information that most of the audience is not familiar with. Explanation (a special order parameter) in the framework of intersection about who Sullivan is explains why he can make predictions about the development of the economy and, therefore, why readers should trust 
these forecasts. Thus, the function of pragmatic influence is also fulfilled.

Subordination is present when propositions are included in the scope of a more general description of the referent. The subordination order parameter is illustrated in Figure 3. For example, the Confederation of British Industry reposts the message of the British economist Alpesh Paleja, in whose post we can see subordination.

Despite pick-up in headline employment, still signs of a softening in the labour mkt:

Rise driven entirely by part-time employment (more so PT self-employed)

Also driven by pick-up in employment among $65+$ - youth employment still falling

Vacancies still falling

The main propositions that make up the content of this discourse are as follows:

a) increase in the level of basic employment

b) signs of mitigation

c) part-time employment is the reason

d) job growth for senior citizens

e) reduction in the number of vacancies

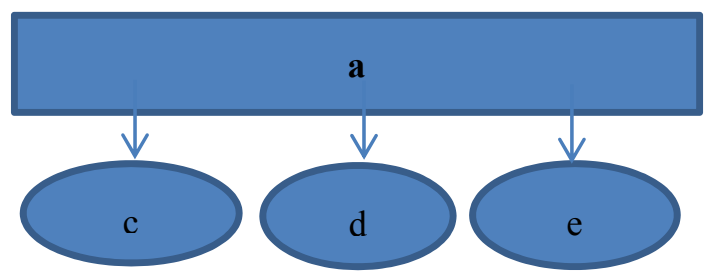

Figure 3. General order parameter-subordination $(\mathrm{a}-\mathrm{c}),(\mathrm{a}-\mathrm{d}),(\mathrm{a}-\mathrm{e})$

The equilibrium state of the system of meanings is indicated by the proposition "job growth". Relative chaotisation of the functional space is observed with the introduction of the proposition "mitigation in the labor market". The initial thesis is supported by a listing indicating an apparent improvement in the situation in the field of employment. The arguments are connected with the main proposition of the logical-semantic relations of subordination. They allow the system to avoid unnecessary fluctuations and maintain stability, that is, confirm the fact of negative trends in the labor market.

Logical-semantic relations of exception can usually be found in the format of a longer discussion, when the volume of the statement allows to switch from one topic to another. In the genre of small-format text they hardly ever occur.

Thus, our main hypothesis is proved by the fact that at pragmatic level small-format texts (Twitter posts) are organised according to a certain set of logical and semantic relations.

\subsubsection{Special Order Parameters}

Special order parameters are, in contrast to logical-semantic ones, pragma-semantic relations between propositions. They can be combined with general order parameters.

Thus, explanation is the relationship of equal volume propositions with the aim of interpreting and eliminating communicative insufficiency (Ponomarenko, 2004.) The explanation amounted to $18 \%$ of the cases from continuous sampling of examples. One of them is presented on the Financial Times Twitter.

Malaysia levels palm oil demands over post-Brexit trade deal. UK must relax EU enviromental policy on crop for agreement, says PM Mahathir.

A discourse system can maintain its functionally stable state with the help of an order parameter (pragma-semantic connection) of explanation. So, in the following example, the first part of the tweet is a message containing several propositions, starting with participation of Malaysia in after-Brexit trade deal and putting forward requirements for palm oil (the EU to limit the supply of the latter to its territory) and ending with the reciprocal requirement of Malaysia. When perceiving this passage, there appears a gap arises at the cognitive 
functional level, as to what the requirements for palm oil are. The verbal form in which the author puts on his message is subject to the genre-stylistic requirements of this type. Nevertheless, in accordance with the laws of functional linguosynergetics, this gap should be eliminated due to self-regulatory properties of discourse. Here the order parameter of explanation plays an important role.

The second sentence clarifies the system of meanings, replenishing causal relationships and supplementing it with a large number of additional meanings. So, in the volume of only two sentenses, information is provided that the EU pursued an environmental protection policy, that Great Britain is looking for deals with Malaysia, that the latter puts forward its demands, that a new perspective opens up in relations between countries in connection with the Great Britain's exit from the EU. Obviously, we observe pragma-semantic increments that nonlinearly arise in the perception of discourse.

Another order parameter, extension consists in nomination of a fact and a broader designation of the situation while the fact is included in it. Extension accounts for $16 \%$ of the studied examples. In the following example, extension helps to avoid repeating the same thought.

Democracies need retooling if they are to survive. They can be modernised and restored, though never to permanent, perfect health.

Functionally, in a business microblog, extension fulfils the function of conveying the message. From the point of view of pragma-semantic evolution, this passage demonstrates the presence of semantic excessiveness and shows how the system gets rid of "odd substances", information that does not correspond to the direction of development to the chosen functional attractor.

So, the statement about the possibility of modernising democracy corresponds to a given motion vector (proof of the thesis about the need for change). The mention that changes will not lead to a permanent and ideal result (never to permanent, perfect health) plays the role of a chaotic element. However, its influence is not critical. In synergetics this phenomenon is called dissipation-scattering of matter outside in the process of self-organisation, and in linguosynergetics - these are chaotic elements that inevitably come into the system when interacting with the external environment, in this case, with the communicative situation. Also, the external environment for the discourse system can serve as consciousness of communicants and language (Ponomarenko, 2004).

The order parameter "causation" accounts for $12 \%$ of the sources studied. This pragma-semantic relationship indicates cause-consequence relationships. Functioning of causation is associated with such a function of a business microblog as explanation. It determines its wide usage, since not only the message is important, but also its interpretation.

So, in the following example, causation is involved in self-organisation of discourse on low interest rates.

Low interest rates are the scourge of the poor and vulnerable. Most households have no hope of accumulating savings; they are better off being profligate.

The pragmatic potential lies in the conflict of concepts "profligate" and "the poor". This proposition serves as a chaotic element in the system that seeks a communicative attractor (the goal is to prove that low interest rates harm socially unprotected people). Advising the poor to be wasteful, the author paves the way for explanation. Causation becomes a stabilising element, linking conflicting concepts, and takes the discourse system to a new level of ordering.

Pragmatic commentary ( $23 \%$ of the sources studied) is represented by relationships in which the statement expresses the perception of the situation. For example, in the next tweet, subsequent propositions, using pragmatic commentary, create the pragmatics of condemnation.

How cool do you keep your house?

- Cool enough to cause carbon dioxide emissions to rise another $2 \%$ in 2018

- Cool enough to use 9\% of global electricity demand

\section{- Cool enough to create more emissions that will lead to even hotter temperatures}

At the same time, the communicative purpose of the statement is not expressed directly, but by the combination of all means of speech expression, mutually reinforcing each other: by repeating the evaluative adjective cool in the question and the answer, by grammatical repetition (adjective + infinitive: cool enough to create, to cause, to use), indicating the consequences of the actions, anaphora, contrasting (cool-hot), collision of positive connotations (cool house) with negative connotations (use electricity, more emissions, hotter temperatures). The 
pragmatic commentary order parameter contributes to evolution of the system of meanings from a seemingly innocuous question to a new equilibrium state of condemnation and irony at the end.

Obviously, with a linear perception of the question-answer sequence, it would not be possible to achieve the proper pragmatic effect. As can be seen from this example, it is much more efficient not to directly state the dangers of air conditioning systems, but to use more complex methods of speech influence.

The following order parameters similarly participate in the evolution of the semantic space of the microblog discourse. Since they are less common in empirical material, we dwell on them briefly.

Specification order parameter ( $5 \%$ of examples) is a functional relationship between statements, one of which contains a general judgment, while the second clarifies it through the nomination of a concrete manifestation of the general situation, for example

US Treasury gets cool response to idea of 'century bond'. Analysts say ultra-long debt could be illiquid and not significantly cut borrowing costs

Sequence is a relationship that reflects the direct or reverse course of a situation. This order parameter $(8 \%$ of examples) is associated with a logical connection between two or more consecutive events. For example,

Veggie burgers were living an idyllic little existence. Then they got caught in a war over the future of meat.

An alternative is a relationship describing options for development of propositions. So, in the following example, two options for employing doctors are considered. The communicative goal of the author is to draw attention to the trend towards job loss.

While the trend toward doctors becoming employees continues, it has slowed. Meanwhile, another trend is afoot: Doctors are also leaving employment at record rates. Employed vs independent doctors: Numbers don't tell the whole story

Contrast represents relations revealing the features of one object in relation to another. For example, John McDonnell uses opposition in his tweet to discredit the policies of the conservative party. Pragma-semantic relationships of contrast streamline the discourse system in accordance with the given goal.

This important analysis by @NEF shows that only an ambitious plan for economic transformation, of the kind Labour proposes, will lift the UK out of the productivity crisis that the Tories have left us in.

Switching as an order parameter demonstrates the absence of common elements in propositions compared.

The Single Market, Britain's big achievement in the EU, is one of the EU's greatest successes. And having been a driving force in leading the EU in setting it up, we now plan to walk away. Time for a rethink. Time for the People's Vote.

Thus, in the message of the European Commission on Britain's exit from the EU, the proposition about Britain's participation in the EU's success is not directly related to the need to vote again. Nevertheless, when arranging arguments in a certain direction (the functional attractor is the conviction that it is necessary to change the decision to leave the EU), they become cause and effect. So, one can again see the important role of verbal and pragmatic tools in shaping the desired speech impact in public discourse.

\section{Discussion. Frequency of Order Parameters Peculiar to a Business Microblog}

We also conducted an analysis of the frequency of special pragma-semantic relationships in business tweets. Among them, the following were most frequent: explanation, expansion, causation, pragmatic commentary (Ponomarenko, 2016; Radyuk \& Litvinov, 2018). The quantitative and percentage ratio of various order parameters is given in Table 1. The reasons why the first four order parameters are more common than others lie in the sphere of pragmatics and stylistics: business relations and phenomena are most often made public for the purpose of explaining and interpreting them, and, therefore, forming a certain attitude towards them.

Being a platform for expressing opinions, a business microblog becomes a place for discussion of controversial and sometimes provocative facts, and causation order parameter quite often participates in such semantic transformations.

Pragmatic commentary, the most frequent relationship, accompanies most business-related tweets. Online communication is a platform for open expression of positions. This is very organically correlated with business discourse as a type of institutional discourse that adapted to the medium - the instant means of transmitting the message. In rare cases, discourse is actualised without reflecting the relationship to the signified object. In online discourse, such functions of pragmatic commentary as expression of opinion, skepticism, irony, humor, condemnation, appeal, curse, praise and others are quite clearly manifested. 
The statistic analysis allows to substantiate our secondary hypothesis - that in the register of business microblogging the set of special order parameters is limited by several most frequent relations.

Table 1. Special order parameters in business microblogs

\begin{tabular}{|c|c|c|}
\hline & Examples, items & Percentage, $\%$ \\
\hline clarification & 28 & 18 \\
\hline extension & 25 & 16 \\
\hline causation & 19 & 12 \\
\hline pragmatic commentary & 36 & 23 \\
\hline specification & 8 & 5 \\
\hline sequence & 13 & 8 \\
\hline contrast & 16 & 10 \\
\hline alternative & 7 & 5 \\
\hline switching & 4 & 3 \\
\hline Total & 158 & 100 \\
\hline clarification & घextension & causation \\
\hline w pragmatic commentary & specification & nequence \\
\hline contrast & alternative & switching \\
\hline
\end{tabular}

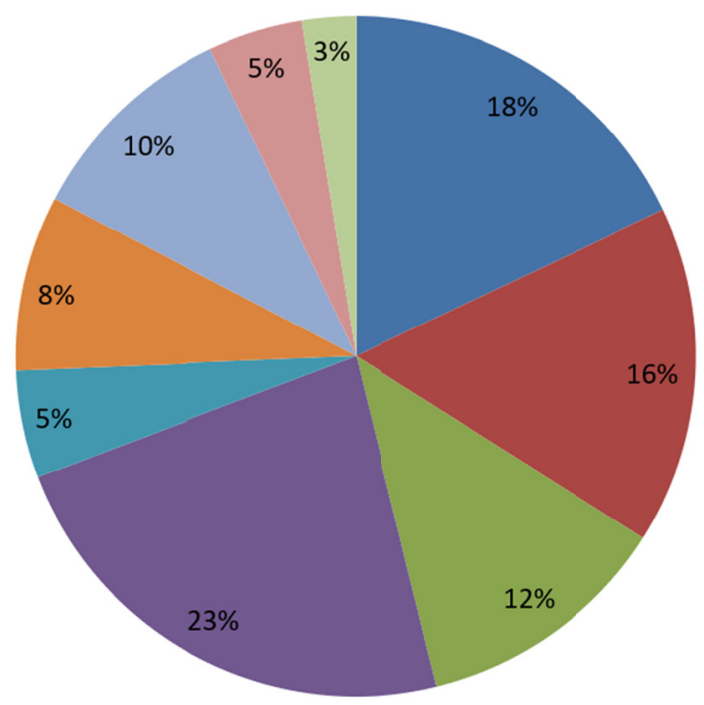

Figure 4. Percentage of special order parameters

\section{Conclusions}

This study showed the features of business discourse functioning in the online register. As it turned out, self-organisation of functional-pragmatic field of discourse is reflected in a limited set of combinations that develop between propositions at the logical-semantic level (general order parameters) and the pragma-semantic level (private order parameters).

We can conclude that an understanding of functional organisation of a business text can help to master the techniques of persuasion and effective writing. With modern pace of ICT development, it is impossible to isolate from the digital method of communication, and in this area, there are technologies aimed at enhancing speech influence and the impact on the consciousness of the audience. With the help of functional analysis of messages on business topics, it was possible to identify the main logical and semantic links between them-clarification, extension, causation and pragmatic commentary. Their predominance is explained by the nature of the information transmitted through Twitter-informing, explanation and formation of a certain pragmatic vision. Structural features of the microblogging genre include brevity, polycode nature, hypertextuality, situationality 
and high expressivity. As analysis has shown, structural properties are directly related to semantic ones.

Consideration of small-format business texts in a linguistic-synergetic perspective reveals to researchers the possibility of studying functioning of discourse system as a unity of messages and comments in social networks, further analysis of successful speech influence and representation of collective consciousness in a public communicative space.

\section{Acknowledgments}

The publication has been prepared with the support of the "RUDN University Program 5-100".

\section{References}

Akhrenova, N. A. (2011). Linguistic features of microblogging. Almanac of Modern Science and Education, 9(52), 119-122.

Barkovich, A. A. (2015). Internet discourse: metalanguage models of practice. Vestnik Volgogradskogo Gosudarstvennogo Universiteta. Seriya 2-Yazykoznanie, 14(5), 171-183. https://doi.org/10.15688/jvolsu2.2015.5.21

Bhatia, V. (1993). Analysing Genre. London: Routledge. https://doi.org/10.4324/9781315844992

Boldovskaya, N. V., \& Zvonova, E. A. (2015). Age factor in English internet discourse. Vestnik Rossiiskogo Universiteta Druzhby Narodov-Seriya Lingvistika-Russian Journal of Linguistics, 3, 122-131.

Dijk, T. van. (1981). Studies in the Pragmatics of Discourse. The Hague. https://doi.org/10.1515/9783110826142

Dubovsky, Y. A., \& Zagrayevskaya, T. B. (2018). Variability of colon and dash usage in English and Russian internet business discourse contexts. Yazyk $i$ Kultura-Language and Culture, 44, 29-43. https://doi.org/10.17223/19996195/44/2

Eleta, I., \& Golbeck, J. (2014). Multilingual use of Twitter: Social networks at the language frontier. Computers in Human Behavior, 41, 424-432. https://doi.org/10.1016/j.chb.2014.05.005

Gritsenko, L., \& Demidova, T. A. (2018). The discrediting speech strategy in internet communication (on the example of the use of trolling). Vestnik Tomskogo Gosudarstvennogo Universiteta Filologiya-Tomsk State University Journal of Philology, 55, 29-42. https://doi.org/10.17223/19986645/55/3

Gunnarsson, B.-L. (2014). Business discourse in the globalized economy: The construction of an attractive workplace culture on the internet. Discourse in Context: Contemporary Applied Linguistics, 3, 91-112.

Haken, H. (1996). Principles of brain functioning. A synergetic approach to brain activity, behavior and cognition. Springer, Berlin, Heidelberg. https://doi.org/10.1007/978-3-642-79570-1

Halliday, M. A. K. (2004). Introduction: how big is a language? on the power of language. In J. J. Webster (Ed.), The Language of Science (Volume 5). London and New York: Continuum.

Halliday, M. A. K., \& Hasan, R. (1974). Cohesion in English. London: Longman.

Jenks, Ch. J. (2019). Talking trolls into existence: On the floor management of trolling in online forums. Journal of Pragmatics, 143, 54-64. https://doi.org/10.1016/j.pragma.2019.02.006

Kharkovskaya, A. A., Ponomarenko, E. V., \& Radyuk, A. V. (2017). Minitexts in modern educational discourse: functions and trends. Training Language and Culture, 1(1), 62-76. https://doi.org/10.29366/2017tlc.1.1.4

Khramchenko, D. S. (2015). Planning the functional field of business English discourse: linguosynergetic approach. Issues of Applied Linguistics, 18, 151-163.

Khramchenko, D. S. (2018). Teaching synergy of pragmatic impact in modern English discourse (pp. 89398942). In ICERI2018 Proceedings, 11th International Conference of Education, Research and Innovation. Seville, Spain. https://doi.org/10.21125/iceri.2018.0647

Khramchenko, D. S. (2019). Evolution of business English: linguistic problems and teaching practice (pp. 12921296). In INTED2019 Proceedings, Valencia, Spain: IATED. https://doi.org/10.21125/inted.2019.0411

Lebedeva, I. S., \& Orlova, S. N. (2019). Semantics and pragmatics of the double modal 'might could'. Training Language and Culture, 3(2), 71-84. https://doi.org/10.29366/2019tlc.3.2.5

Litvinov, A. V., Burikova, S. A., \& Khramchenko, D. S. (2017). Phrasal verbs as learning material in Business English courses for students majoring in Linguistics. Training Language and Culture, 1(4), 84-98. https://doi.org/10.29366/2017tlc.1.4.6 
Malakhova, V. L. (2017). Functional properties of possessive nominations and their impact on the pragmatic and semantic systemity of the English discourse (Book 3. Volume II, pp. 745-752). In 4th International Multidisciplinary Scientific Conference on Social Sciences and Arts SGEM2017. Science and Society: Conference Proceedings. Albena, Bulgaria. https://doi.org/10.5593/sgemsocial2017/32/S14.096

Malyuga, E. (2019). Between turn and sequence: turn-initial particles across languages (a review). Training Language and Culture, 3(1), 105-107. https://doi.org/10.29366/2019tlc.3.1.7

Malyuga, E. N. (2020). Functional approach to professional discourse exploration in linguistics. Springer. https://doi.org/10.1007/978-981-32-9103-4

Malyuga, E. N., \& Tomalin, B. (2017). Communicative strategies and tactics of speech manipulation in intercultural business discourse. Training Language and Culture, 1(1), 28-45. https://doi.org/10.29366/2017tlc.1.1.2

Nikitina, O. A., Gudkova, O. A., \& Sander, F. (2018). Internet meme as a multimodal phenomenon of the German internet-discourse. Yazyk I Kultura-Language and Culture, 43, 74-87. https://doi.org/10.17223/19996195/43/5

Orlova, T. G. (1998). Pedagogical speech science. Moscow: Flinta, Science. Retrieved from https://ped_recheved.academic.ru

Perevezentseva, Y. S. (2014). Lexical and syntactic features of English Internet communication (using the microblog Twitter as an example). Volga Scientific Herald, 9(37), 84-87.

Perez-Llantada, C. (2016). How is the digital medium shaping research genres? Some cross-disciplinary trends. ESP Today-Journal of English for Specific Purposes at Tertiary Level, 4(1), 22-42.

Ponomarenko, E. V. (2004). Functional systemacy of discourse (based on English). M.: MSU.

Ponomarenko, E. V. (2016). Functional properties of English discourse in terms of linguosynergetics (Book 1, Vol. 3, pp. 355-362). In 3rd International Multidisciplinary Scientific Conference on Social Sciences and Arts SGEM 2016 Proceedings. Bulgaria, Albena.

Ponomarenko, E. V. (2018). The notion of functional synergism in linguistics (Book 1, Vol. 5, pp. 501-508). In 5th International Multidisciplinary Scientific Conference on Social Sciences and Arts SGEM 2018 Proceedings. Austria, Vienna. https://doi.org/10.5593/sgemsocial2018H/31/S10.063

Radyuk, A. V., \& Litvinov, A. V. (2018). Self-organization of functional space of public speech in the context of American identity. Philological Sciences. Issues of Theory and Practice, 12-2(90), 367-371. https://doi.org/10.30853/filnauki.2018-12-2.36

Runkehl, J. (2018). Language in media discourse: progression - eruption - regression? Muttersprache, 128(1), $17-28$.

Sampietro, A. (2019). Emoji and rapport management in Spanish WhatsApp chats. Journal of Pragmatics, 143, 109-120. https://doi.org/10.1016/j.pragma.2019.02.009

Sardinha, T. B. (2018). Dimensions of variation across Internet registers. International Journal of Corpus Linguistics, 23(2), 125-157. https://doi.org/10.1075/ijcl.15026.ber

Savitsky, V. M., \& Ivanova, A. G. (2018). The role of cultural scripts in non-native speech generation. Training Language and Culture, 2(4), 70-83. https://doi.org/10.29366/2018tlc.2.4.5

Scalzilli, G. de C. (2018). Meme and aphorization: a discursive approach to digital iconotextuality. Cadernos de Estudos Linguisticos, 60(3), 795-807. https://doi.org/10.20396/cel.v60i3.8650832

Wildgen, W. (1990). Basic principles of self-organization in language. In Synergetics of Cognition (pp. 415-426). L., P., Tokyo, Hong Kong: Springer-Verlag Berlin Heidelberg. https://doi.org/10.1007/978-3-642-48779-8_24

\section{Copyrights}

Copyright for this article is retained by the author, with first publication rights granted to the journal.

This is an open-access article distributed under the terms and conditions of the Creative Commons Attribution license (http://creativecommons.org/licenses/by/4.0/). 